\title{
Pengaruh Ketidakseimbangan Beban Terhadap Arus Netral dan Arus Ground pada Trafo 1 dan Trafo 2 pada Beban Puncak Sesaat
}

\author{
Ruliyanto $^{1^{*}}$ \\ ${ }^{1}$ Program Studi Teknik Elektro Universitas Nasional, Jakarta 12520 \\ *Korespondensi penulis: rullysitepu@gmail.com
}

\begin{abstract}
Abstrak. Transformator atau trafo adalah salah satu komponen utama peralatan gedung untuk menurunkan tegangan sesuai dengan kebutuhan. Permasalahan yang sering dijumpai adalah masalah ketidakseimbangan beban. Umumnya penyebab ketidakseimbangan adalah pada beban-beban satu fasa pada jaringan. Akibat ketidakseimbangan beban tersebut munculah arus di netral trafo. Arus yang mengalir di netral trafo ini menyebabkan terjadinya losses (rugi-rugi), yaitu losses akibat adanya arus netral pada penghantar netral trafo dan losses akibat arus netral yang mengalir ke ground. Setelah dianalisis, terjadi ketidakseimbangan beban pada Trafo 1 sebesar 5.23\%, akan berakibat muncul arus netral $\mathrm{I}_{\mathrm{N}}$ sebesar 300 ampere, dan losses akibat arus netral $\mathrm{I}_{\mathrm{G}}$ yang mengalir ke tanah sebesar $0.15 \%$. Kapasitas daya yang terpakai saat ini sebesar $84.65 \%$.
\end{abstract}

Keywords: tranformer, load, neutral current, ground current.

\section{PENDAHULUAN}

Pertumbuhan properti di Indonesia meningkat secara signifikan. Seiring dengan laju pertumbuhan pembangunan properti khususnya bangunan bertingkat maka dituntut adanya sarana dan prasarana yang mendukungnya seperti tersedianya tenaga listrik [1]. PT PLN merupakan perusahaan utama yang mensuplai kebutuhan listrik di seluruh Indonesia. Saat ini tenaga listrik merupakan kebutuhan yang utama, baik untuk kehidupan sehari-hari maupun untuk kebutuhan industri. Untuk mentransportasikan tenaga listrik dibutuhkan tegangan tinggi, tujuan utamanya untuk mengecilkan arus yang ditransmisikan dan pada akhirnya dibutuhkan diameter kabel distribusi yang kecil juga. Besarnya diameter kabel transmisi dipengaruhi dengan besarnya arus yang listrik yang akan dihantarkan [2].

Dalam pendistribusian tenaga listrik gedung, terjadi pembagian beban-beban yang pada awalnya merata, tetapi akan terjadi ketidakseimbangan akibat ketidakserempakan waktu penyalaan beban-beban. Hal ini berakibat terjadinya ketidakseimbangan beban setiap fasa (fasa $\mathrm{R}$, fasa $\mathrm{S}$, dan fasa $\mathrm{T}$ ) dan inilah yang menyebabkan terjadinya rugi-rugi arus yang mengalirnya pada trafo di jaringan netral trafo dan jaringan grounded trafo.

\section{METODE PENELITIAN}

Transformator atau sering disebut sebagai trafo merupakan suatu alat listrik yang mengubah tegangan arus bolak-balik dari tegangan satu ke tegangan lain melalui suatu gandengan magnet dan berdasarkan prinsip-prinsip induksi-elektromagnet. Transformator terdiri atas sebuah inti, yang terbuat dari besi berlapis dan dua buah kumparan, yaitu kumparan primer dan kumparan sekunder. Ada dua jenis trafo, step up untuk menaikkan tegangan dan step down untuk menurunkan tegangan. Dan dalam kebutuhan gedung umumnya digunakan trafo step down yang berfungsi untuk menurunkan tegangan dari tegangan menengah ke tegangan rendah. 
Penggunaan transformator yang sederhana dan handal memungkinkan dipilihnya tegangan yang sesuai dan ekonomis untuk tiap-tiap keperluan serta merupakan salah satu sebab penting bahwa arus bolak-balik sangat banyak dipergunakan untuk pembangkitan dan penyaluran tenaga listrik. Prinsip kerja transformator adalah berdasarkan hukum Ampere dan hukum Faraday, yaitu: arus listrik dapat menimbulkan medan magnet dan sebaliknya medan magnet dapat menimbulkan arus listrik. Jika pada salah satu kumparan pada transformator diberi arus bolak-balik maka jumlah garis gaya magnet berubah-ubah. Akibatnya pada sisi primer terjadi induksi. Sisi sekunder menerima garis gaya magnet dari sisi primer yang jumlahnya berubah-ubah pula. Maka di sisi sekunder juga timbul induksi, akibatnya antara dua ujung terdapat beda tegangan $[2,3]$.

\section{Perhitungan Arus Beban Penuh Transformator}

Daya transformator bila ditinjau dari sisi tegangan tinggi (primer) dapat dirumuskan sebagai berikut:

$$
\mathrm{S}=\sqrt{ } 3 . \mathrm{V} . \mathrm{I}
$$

dimana:

$\mathrm{S}=$ daya transformator $(\mathrm{kVA})$

$\mathrm{V}=$ tegangan sisi primer transformator $(\mathrm{kV})$

$\mathrm{I}=$ arus jala-jala $(\mathrm{A})$

Sehingga untuk menghitung arus beban penuh (full load) dapat menggunakan rumus:

$$
I_{F L}=\frac{S}{\sqrt{3} V}
$$

dimana:

$$
\begin{aligned}
& \mathrm{I}_{\mathrm{FL}}=\operatorname{arus} \text { beban penuh }(\mathrm{A}) \\
& \mathrm{S}=\text { daya transformator }(\mathrm{kVA}) \\
& \mathrm{V}=\text { tegangan sisi sekunder transformator }(\mathrm{kV})
\end{aligned}
$$

\section{Losses (rugi-rugi) Akibat Arus Netral pada Penghantar Netral Transformator}

Sebagai akibat dari ketidakseimbangan beban antara tiap-tiap fasa pada sisi sekunder trafo (fasa R, fasa S, fasa T) mengalirlah arus di netral trafo[4]-[6]. Arus yang mengalir pada penghantar netral trafo ini menyebabkan losses (rugi-rugi). Losses pada penghantar netral trafo ini dapat dirumuskan sebagai berikut:

$$
P_{N}=I_{N}^{2} \cdot R_{N}
$$

dimana:

$$
\begin{aligned}
& P_{N}=\text { losses } \text { pada penghantar netral trafo (watt) } \\
& I_{N}=\text { arus yang mengalir pada netral trafo }(\mathrm{A}) \\
& R_{N}=\text { tahanan penghantar netral trafo }(\Omega)
\end{aligned}
$$

Sedangkan losses yang diakibatkan karena arus netral yang mengalir ke tanah (ground) dapat dihitung dengan perumusan sebagai berikut:

$$
P_{G}=I_{G}^{2} \cdot R_{G}
$$

dimana:

$P_{G}=$ losses akibat arus netral yang mengalir ke tanah (Watt)

$I_{G}=$ arus netral yang mengalir ke tanah (Ampere)

$R_{G}=$ tahanan pembumian netral trafo $(\mathrm{Ohm})$

\section{Ketidakseimbangan Beban}

Yang dimaksud dengan keadaan seimbang adalah suatu keadaan di mana:

- Ketiga vektor arus / tegangan sama besar.

- Ketiga vektor saling membentuk sudut $120^{\circ}$ satu sama lain.

Sedangkan yang dimaksud dengan keadaan tidak seimbang adalah keadaan di mana salah satu atau kedua syarat keadaan seimbang tidak terpenuhi [2].

Kemungkinan keadaan tidak seimbang ada 3 yaitu: 
- Ketiga vektor sama besar tetapi tidak membentuk sudut $120^{\circ}$ satu sama lain.

- Ketiga vektor tidak sama besar tetapi membentuk sudut $120^{\circ}$ satu sama lain.

- Ketiga vektor tidak sama besar dan tidak membentuk sudut $120^{\circ}$ satu sama lain.

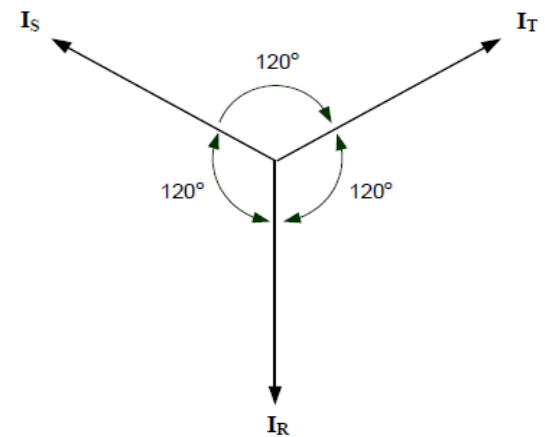

(a)

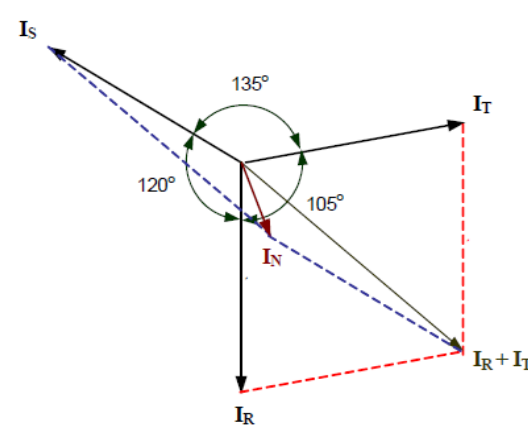

(b)

GAMBAR 1. Vektor diagram arus.

Gambar 1(a) menunjukkan vektor diagram arus dalam keadaan seimbang. Di sini terlihat bahwa penjumlahan ketiga vektor arusnya $\left(I_{R}, I_{S}, I_{T}\right)$ adalah sama dengan nol sehingga tidak muncul arus netral $\left(I_{N}\right)$. Sedangkan pada Gambar 1(b) menunjukkan vektor diagram arus yang tidak seimbang. Di sini terlihat bahwa penjumlahan ketiga vektor arusnya $\left(I_{R}\right.$, $\left.I_{S}, I_{T}\right)$ tidak sama dengan nol sehingga muncul sebuah besaran yaitu arus netral $\left(I_{N}\right)$ yang besarnya bergantung dari seberapa besar faktor ketidakseimbangannya [6, 7].

\section{Penyaluran dan Susut Daya}

Misalnya daya sebesar $P$ disalurkan melalui suatu saluran dengan penghantar netral. Apabila pada penyaluran daya ini arus-arus fasa dalam keadaan seimbang, maka besarnya daya dapat dinyatakan sebagai berikut:

$$
P=3 .[V] .[I] \cdot \cos \phi
$$

dengan $P=$ daya pada ujung kirim

$V=$ tegangan pada ujung kirim

$\cos \phi=$ faktor daya

Daya yang sampai ujung terima akan lebih kecil dari $P$ karena terjadi penyusutan dalam saluran. Jika $[I]$ adalah besaran arus fasa dalam penyaluran daya sebesar $P$ pada keadaan seimbang, maka pada penyaluran daya yang sama tetapi dengan keadaan tak seimbang besarnya arus-arus fasa dapat dinyatakan dengan koefisien a, b dan c sebagai berikut:

$$
\begin{aligned}
& {\left[I_{R}\right]=a[I]} \\
& {\left[I_{S}\right]=b[I]} \\
& {\left[I_{T}\right]=c[I]}
\end{aligned}
$$

dengan $I_{R}, I_{S}$ dan $I_{T}$ berturut-turut adalah arus di fasa R, S dan T $[6,8]$.

Bila faktor daya di ketiga fasa dianggap sama walaupun besarnya arus berbeda, besarnya daya yang disalurkan dapat dinyatakan sebagai:

$$
P=(a+b+c) \cdot[V] \cdot[I] \cdot \cos \phi
$$

Apabila persamaan (7) dan persamaan (5) menyatakan daya yang besarnya sama, maka dari kedua persamaan itu dapat diperoleh persyaratan untuk koefisien $\mathrm{a}, \mathrm{b}$, dan c yaitu:

$$
a+b+c=3
$$

dimana pada keadaan seimbang, nilai $a=b=c=1$.

\section{PROSES PENELITIAN}

Pada tahap awal dilakukan pengumpulan data teknis. Hal ini dilakukan dengan mengambil dari spesifikasi alat atau pengukuran secara langsung di peralatan yang sudah 
ada. Spesifikasi trafo 1 dan trafo 2 yang ada diberikan pada tabel 1 dan diperjelas dengan gambar 2 sesuai name plate pada unit tranformer.

TABEL 1. Spesifikasi teknis trafo 1 dan trafo 2.

\begin{tabular}{lclc}
\hline & Trafo 1 & & Trafo 2 \\
\hline Buatan Pabrik & $:$ TRAFINDO & Buatan Pabrik & $:$ TRAFINDO \\
\hline Tipe & $:$ Indoor & Tipe & $:$ Indoor \\
\hline Daya & $: 3000 \mathrm{kVA}$ & Daya & $: 2500 \mathrm{kVA}$ \\
\hline Tegangan Kerja & $: 21 / 20,5 / 20 / 19,5 / 19 \mathrm{kV} / 400 \mathrm{~V}$ & Tegangan Kerja & $: 21 / 20,5 / 20 / 19,5 / 19 \mathrm{kV} / 400 \mathrm{~V}$ \\
\hline Arus & $: 6,8-359 \mathrm{~A}$ & Arus & $: 6,8-359 \mathrm{~A}$ \\
\hline Hubungan & $:$ Dyn5 & Hubungan & $:$ Dyn5 \\
\hline Impedansi & $: 7,5 \%$ & Impedansi & $: 7,5 \%$ \\
\hline Trafo & $: 1 \times 3$ phasa & Trafo & $: 1 \times 3$ phasa \\
\hline
\end{tabular}

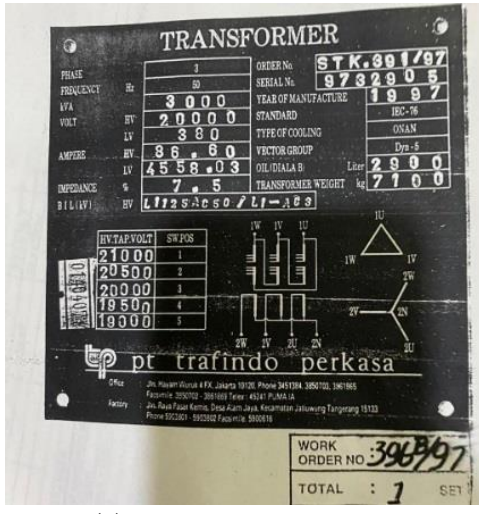

(a)

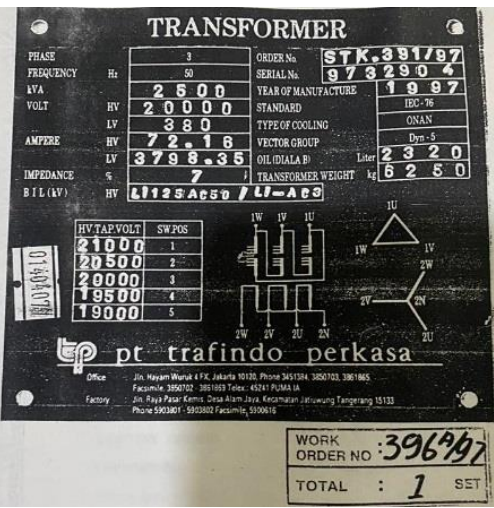

(b)

GAMBAR 2. Spesifikasi Trafo sesuai dengan name plate: a). Spesifikasi transformer 1 b). Spesifikasi transformer 2 .

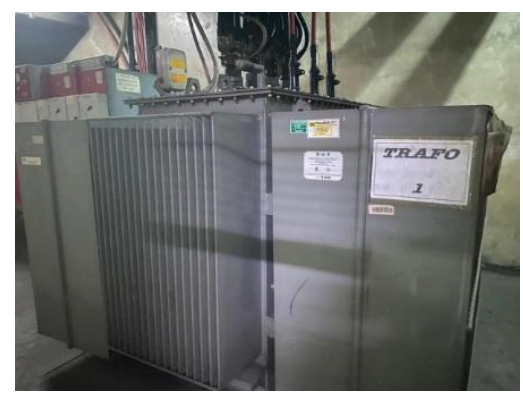

(a)

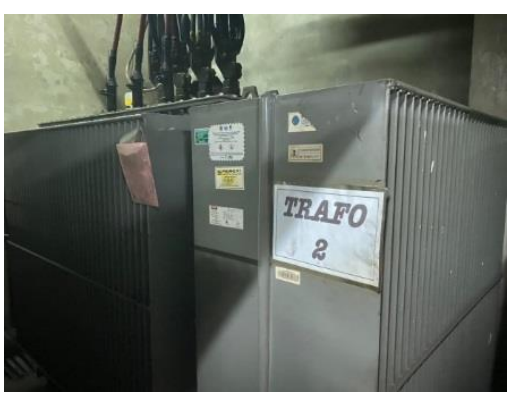

(b)

GAMBAR 3. Tranformator: a). Trafo $3000 \mathrm{kVA}, \mathrm{b}$ ). Trafo $2500 \mathrm{kVA}$.

Dalam gambar 3 diberikan gambaran kondisi fisik dari trafo yang ada dengan kapasitas 3000 kVA dan 2500 kVA merk Trafindo. Gambar 4 menerangkan single line diagram dari sistem trafo yang ada.

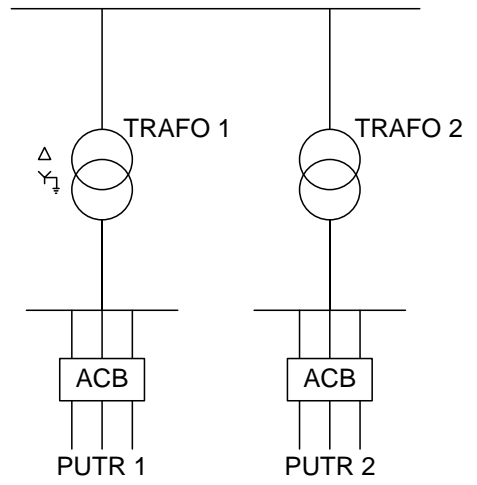

GAMBAR 4. Single line trafo distribusi $3000 \mathrm{kVA}$ dan $2500 \mathrm{kVA}$. 
Metode pengambilan data dengan pengukuran kondisi sesaat pada hari week day saat beban tertinggi pada pukul 15.20 WIB. Hasil pengukuran diberikan pada Tabel 2. Ukuran kawat untuk penghantar netral trafo dan penghantar fasanya sama adalah $300 \mathrm{~mm} 2$ dengan nilai resistansi $\mathrm{R}=0,0601 \Omega / \mathrm{km}$.

TABEL 2. Pengukuran trafo 1 dan trafo 2.

\begin{tabular}{|c|c|c|c|c|c|c|c|c|c|}
\hline \multicolumn{5}{|c|}{ Trafo 1} & \multicolumn{5}{|c|}{ Trafo 2} \\
\hline FASA & $\begin{array}{c}\mathrm{S} \\
(\mathrm{kVA})\end{array}$ & $\begin{array}{c}V_{\text {P-N }} \\
\mathrm{V}\end{array}$ & $\begin{array}{l}\mathrm{I} \\
\mathrm{A} \\
\end{array}$ & $\operatorname{Co} \phi$ & FASA & $\begin{array}{c}\mathrm{S} \\
(\mathrm{kVA})\end{array}$ & $\begin{array}{c}\mathrm{V}_{\mathrm{P}-\mathrm{N}} \\
\mathrm{V}\end{array}$ & $\begin{array}{l}\mathrm{I} \\
\mathrm{A} \\
\end{array}$ & $\operatorname{Co} \phi$ \\
\hline$I_{R}$ & 360.13 & 215 & 1.675 & 0.91 & $I_{R}$ & 448.00 & 215 & 2010.0 & 0.91 \\
\hline$I_{S}$ & 405.22 & 216 & 1.876 & 0.91 & $I_{S}$ & 451.53 & 216 & 2090.4 & 0.91 \\
\hline$I_{T}$ & 407.20 & 214 & 1.903 & 0.91 & $I_{T}$ & 447.35 & 214 & 2103.8 & 0.91 \\
\hline$I_{N}$ & & \multicolumn{2}{|c|}{$300 \mathrm{~A}$} & & $I_{N}$ & & \multicolumn{2}{|c|}{$300 \mathrm{~A}$} & \\
\hline$I_{G}$ & & \multicolumn{2}{|c|}{$13.50 \mathrm{~A}$} & & $I_{G}$ & & \multicolumn{2}{|c|}{$12.50 \mathrm{~A}$} & \\
\hline$R_{G}$ & & \multicolumn{2}{|c|}{$2.32 \mathrm{ohm}$} & & $R_{G}$ & & \multicolumn{2}{|c|}{$2.72 \mathrm{ohm}$} & \\
\hline$R 300 \mathrm{~mm}$ & & \multicolumn{2}{|c|}{$0.0601 \mathrm{ohm}$} & & $R 300 \mathrm{~mm}$ & & \multicolumn{2}{|c|}{$0.0601 \mathrm{ohm}$} & \\
\hline
\end{tabular}

\section{ANALISIS DATA}

Sesuai dengan hasil pengukuran, maka dapat digambarklan kondisi skema arus trafo 1 dan trafo 2 seperti pada gambar 5. Dalam gambar ideal, $I_{N}$ seharusnya tidak ada arus.

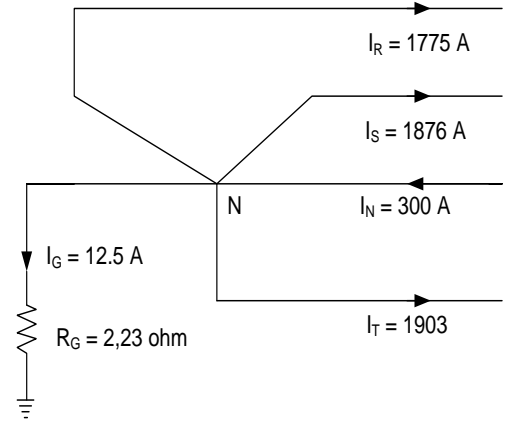

(a)

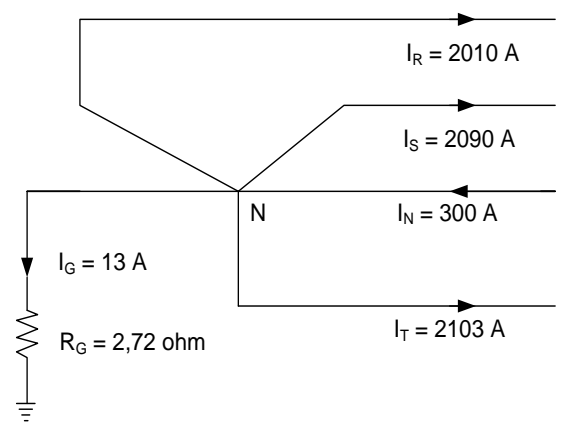

(b)

GAMBAR 5. Skema Aliran Arus di Sisi Sekunder: a). skema aliran arus trafo 1, b). skema arus trafo 2.

\section{Analisa Pembebanan Trafo}

Pada trafo 1, maka pembebanan trafo dapat dihitung dengan,

$$
\begin{aligned}
& \mathrm{S}=3000 \mathrm{kVA} \\
& \mathrm{V}=380 \mathrm{~V} \text { phasa-phasa }
\end{aligned}
$$

maka besarnya arus $I_{F L}$ adalah:

$$
\begin{aligned}
& I_{F L}=\frac{S}{\sqrt{3 X V}}=\frac{3000000}{\sqrt{3} \times 380} \\
&=4545,45 \text { Ampere } \\
& I_{\text {rata }} \text { Trafo } 1=\frac{I_{R}+I_{S}+I_{T}}{3}=\frac{1775+1876+1903}{3} \\
& \quad=1818 \text { Ampere }
\end{aligned}
$$

Sedangkan pada Trafo 2 pembebanan trafo adalah sebagai berikut:

$$
\begin{aligned}
& \mathrm{S}=2500 \mathrm{kVA} \\
& \mathrm{V}=380 \mathrm{~V} \text { phasa-phasa }
\end{aligned}
$$

maka besarnya arus $I_{F L}$ adalah:

$$
\begin{aligned}
I_{F L} & =\frac{S}{\sqrt{3 X V}}=\frac{2500000}{\sqrt{3} \times 380} \\
& =3787,87 \text { Ampere } \\
I_{\text {rata }} & \text { Trafo2 }=\frac{I_{R}+I_{S}+I_{T}}{3}=\frac{2010+2090+2103}{3} \\
& =2067.66 \text { Ampere }
\end{aligned}
$$


Dari perhitungan di atas terlihat bahwa pada trafo 1 pada beban puncak persentase pembebanan sebesar $41.87 \%$. Nilai ini didapat dari pembagian arus tertinggi pada $I_{S}$ sebesar 1903 A dibagi arus tersedia pada Trafo 1 sebesar 4545.45 A.

Dengan perhitungan yang sama, pada trafo 2 pada beban puncak, pembebanan trafo sebesar 55.53\%. Nilai ini adalah rasio antara arus tertinggi pada fasa T sebesar $2103 \mathrm{~A}$ dibagi dengan arus tersedia sebesar $3787.87 \mathrm{~A}$.

Sesuai data pada panel tegangan menengah (PTM) Mal Cijantung, besarnya kapasitas daya listrik PLN sebesar $3030 \mathrm{kVA}$. Ini berarti bahwa arus yang tersedia untuk Mal Cijantung hanya sebesar 4590 A. Bila arus trafo 1 dan trafo 2 digabungkan, maka total besarnya arus yang terpakai adalah $3885.66 \mathrm{~A}$. Ini memberikan pembebanan daya listrik yang ada sebesar $84.65 \%$.

\section{Analisa Ketidak seimbangan Beban pada Trafo}

Pada trafo 1, dengan menggunakan persamaan (6), koefisien a, b, dan c dapat diketahui besarnya, dimana besarnya arus fasa dalam keadaan seimbang (I) sama dengan besarnya arus rata-rata $\left(\mathrm{I}_{\text {rata }}\right)$.

$$
\begin{aligned}
& I_{R}=a . I \text { maka }: \mathrm{a}=\frac{I_{R}}{I}=\frac{I_{R}}{I}=\frac{1675}{1818}=0.921 \\
& I_{S}=b . I \text { maka }: \mathrm{b}=\frac{I_{S}}{I}=\frac{I_{R}}{I}=\frac{1876}{1818}=1.032 \\
& I_{T}=c . I \text { maka }: \mathrm{a}=\frac{I_{T}}{I}=\frac{I_{R}}{I}=\frac{1903}{1818}=1.046
\end{aligned}
$$

Pada keadaan seimbang, besarnya koefisien a, b dan c adalah 1. Dengan demikian, ratarata ketidakseimbangan beban (dalam \%) adalah:

$$
\begin{aligned}
& =\frac{\{|a-1|+|b-1|+|c-1|\}}{3} \times 100 \% \\
& =\frac{\{|0.921-1|+|1.032-1|+|1.046-1|\}}{3} \times 100 \% \\
& =5.23 \%
\end{aligned}
$$

Sedangkan pada trafo 2, menggunakan persamaan (6), koefisien a, b, dan c dapat diketahui besarnya, dimana besarnya arus fasa dalam keadaan seimbang (I) sama dengan besarnya arus rata-rata $\left(\mathrm{I}_{\mathrm{rata}}\right)$.

$$
\begin{aligned}
& I_{R}=a . I \text { maka }: \mathrm{a}=\frac{I_{R}}{I}=\frac{I_{R}}{I}=\frac{2010}{2068}=0.972 \\
& I_{S}=b . I \text { maka }: \mathrm{b}=\frac{I_{S}}{I}=\frac{I_{R}}{I}=\frac{2090}{2068}=1.011 \\
& I_{T}=c . I \text { maka }: \mathrm{a}=\frac{I_{T}}{I}=\frac{I_{R}}{I}=\frac{2103}{2068}=1.017
\end{aligned}
$$

Pada keadaan seimbang, besarnya koefisien a, b dan c adalah 1 . Dengan demikian, ratarata ketidakseimbangan beban (dalam \%) adalah:

$$
\begin{aligned}
& \frac{\{|a-1|+|b-1|+|c-1|\}}{3} \times 100 \% \\
& \quad=1.87 \% 3
\end{aligned}
$$

Dari perhitungan di atas terlihat bahwa baik pada trafo 1 maupun trafo 2 memiliki ketidakeimbangan beban. Trafo 1 mencapai $5.23 \%$ dan pada trafo 2 hanya $1.87 \%$.

\section{Analisa Losses Akibat Arus Netral pada Penghantar Netral Trafo dan Losses Akibat} Arus Netral yang Mengalir ke Tanah

Pada trafo 1, dari tabel pengukuran, dan dengan menggunakan persamaan (3), losses akibat adanya arus netral pada penghantar netral trafo dapat dihitung besarnya, yaitu:

$$
\begin{aligned}
\mathrm{P}_{\mathrm{N}} & =\mathrm{I}_{\mathrm{N}}^{2} \times \mathrm{R}_{\mathrm{N}}=(300)^{2} \times 0,0601 \\
& =5409 \mathrm{Watt} \approx 5,4 \mathrm{~kW}
\end{aligned}
$$

dimana daya aktif trafo $(\mathrm{P})$ :

$$
\begin{aligned}
& \mathrm{P}=\mathrm{S} . \cos \varphi, \text { dimana } \cos \varphi \text { yang digunakan adalah } 0,85 \\
& \mathrm{P}=3000.0,85=2550 \mathrm{~kW}
\end{aligned}
$$

sehingga, persentase losses akibat adanya arus netral pada penghantar netral trafo adalah: 


$$
\% P_{N}=\frac{P_{N}}{P} \times 100 \%=0.21 \%
$$

Losses akibat arus netral $I_{G}$ yang mengalir ke tanah dapat dihitung besarnya dengan menggunakan persamaan (4), yaitu:

$$
\begin{aligned}
P_{G} & =I_{G}{ }^{2} \times R_{G}=(12.5)^{2} \times 2.32=362.5 \text { Watt } \\
& \approx 0.362 \mathrm{~kW}
\end{aligned}
$$

dengan demikian persentase losses-nya adalah:

$$
\% P_{G}=\frac{P_{G}}{P} \times 100 \%=0.015 \%
$$

Pada trafo 2, dari tabel pengukuran, dan dengan menggunakan persamaan (3), losses akibat adanya arus netral pada penghantar netral trafo dapat dihitung besarnya, yaitu:

$$
\begin{aligned}
& \mathrm{PN}=(300)^{2} \times 0 / 0601=5409 \mathrm{Watt} \\
& \approx 5.4 \mathrm{~kW}
\end{aligned}
$$

sehingga, persentase losses akibat adanya arus netral pada penghantar netral trafo adalah:

$$
\% \mathrm{P}_{\mathrm{N}}=\frac{\mathrm{P}_{\mathrm{N}}}{\mathrm{P}} \times 100 \%=0.25 \%
$$

Losses akibat arus netral yang mengalir ke tanah dapat dihitung besarnya dengan menggunakan persamaan (4), yaitu:

$$
\mathrm{P}_{\mathrm{G}}=(13)^{2} \times 2.72=459.68 \approx 0.46 \mathrm{~kW}
$$

dengan demikian persentase losses akibat arus netral yang mengalir ke tanah adalah:

$$
\% \mathrm{P}_{\mathrm{G}}=\frac{\mathrm{P}_{\mathrm{G}}}{\mathrm{P}} \times 100 \%=0.02 \%
$$

TABEL 3. Losses pada trafo.

\begin{tabular}{lcccccccc}
\hline & $\begin{array}{c}\mathbf{R}_{\mathbf{N}} \\
(\mathbf{O h m})\end{array}$ & $\begin{array}{c}\text { Ketidak } \\
\text { seimbangan }\end{array}$ & $\begin{array}{c}\mathbf{I}_{\mathbf{N}} \\
(\mathbf{A})\end{array}$ & $\begin{array}{c}\mathbf{I}_{\mathbf{G}} \\
(\mathbf{A})\end{array}$ & $\begin{array}{c}\mathbf{P}_{\mathbf{N}} \\
(\mathbf{k W})\end{array}$ & $\begin{array}{c}\mathbf{P}_{\mathbf{N}} \\
(\boldsymbol{\%})\end{array}$ & $\begin{array}{c}\mathbf{P}_{\mathbf{G}} \\
(\mathbf{k W})\end{array}$ & $\begin{array}{c}\mathbf{P}_{\mathbf{G}} \\
(\boldsymbol{\%})\end{array}$ \\
\hline Trafo 1 & 0.0601 & $5.23 \%$ & 300 & 12.5 & 5.4 & $0.21 \%$ & 0.362 & $0.15 \%$ \\
Trafo 2 & 0.0601 & $1.87 \%$ & 300 & 13 & 5.4 & $0.25 \%$ & 0.46 & $0.02 \%$ \\
\hline
\end{tabular}

Pada tabel 3 terlihat bahwa semakin besar arus netral yang mengalir di penghantar netral trafo $\left(\mathrm{I}_{\mathrm{N}}\right)$ maka semakin besar losses pada penghantar netral trafo $\left(\mathrm{P}_{\mathrm{N}}\right)$. Demikian pula bila semakin besar arus netral yang mengalir ke tanah $\left(\mathrm{I}_{\mathrm{G}}\right)$, maka semakin besar losses akibat arus netral yang mengalir ke tanah $\left(\mathrm{P}_{\mathrm{G}}\right)$. Dengan semakin besar arus netral dan losses di trafo maka effisiensi trafo menjadi turun.

Dalam penelitian ini perlu dikaji ulang alat ukur, metode pengukuran dan lain-lain. Peneliti sangat sulit mengambil data karena medan yang sulit dan dibutuhkan sample pengukuran yang sebanyak-banyaknya untuk mendapatkan akurasi perhitungan secara detail. Dalam pengukuran arus grounding, peneliti hanya mampu mendapatkan data pada kabel grounding yang ada di tray yang tersedia terdekat, belum pada main grounding masing-masing trafo. Dalam penelitian ini juga belum dibuat perhitungan nominal kerugian atas loss yang terjadi.

\section{KESIMPULAN}

Berdasarkan analisa data di atas, terlihat bahwa pada trafo 1 mengalami ketidakseimbangan beban lebih tinggi dibandingkan pada trafo 2. Sesuai tabel 3, semakin besar ketidakseimbangan beban pada trafo maka arus netral yang mengalir ke tanah $\left(\mathrm{I}_{\mathrm{G}}\right)$ dan losses trafo tiang semakin besar. Setelah dianalisis, terjadi ketidakseimbangan beban pada trafo 1 sebesar 5.23\%, akan berakibat muncul arus netral $\mathrm{I}_{\mathrm{N}}$ sebesar 300 Ampere, dan losses akibat arus netral $\mathrm{I}_{\mathrm{G}}$ yang mengalir ke tanah sebesar $0.15 \%$. Kapasitas daya yang terpakai saat ini sebesar $84.65 \%$. Salah satu cara mengatasi losses arus netral adalah dengan membuat beban dalam fasa seimbang sehingga arus yang hilang dari kabel netral menjadi 0 . 


\section{REFERENSI}

[1] R. Efrida, "Pengaruh Setback Pada Bangunan Dengan Soft Story Terhadap Kinerja Struktur Akibat Beban Gempa," Educational Building, vol. 4, no. 1, pp. 62-68, 2018.

[2] J. Sentosa Setiadji, T. Machmudsyah, and Y. Isnanto, "Pengaruh Ketidakseimbangan Beban Terhadap Arus Netral dan Losses pada Trafo Distribusi," Jurnal Teknik Elektro, vol. 7, no. 2, 2008.

[3] E. F. Teknik, "Analisa Pengaruh Ketidakseimbbangan Beban Terhadap Arus Netral dan Loses pada Trafo Distribusi Studi Kasus Pada PT PLN (Persero) Rayon Blora," 2018.

[4] V. Jones and J. C. Balda, "Correcting current imbalances in three-phase four-wire distribution systems," Conference Proceedings - IEEE Applied Power Electronics Conference and Exposition - APEC, vol. 2016-May, pp. 1387-1391, 2016.

[5] M. D. Tobi, “Analisis Pengaruh Ketidakseimbangan Beban Terhadap Arus Netral Dan Losses Pada Transformator Distribusi Di Pt Pln (Persero) Area Sorong," Electro Luceat, vol. 4, no. 1, p. 5, 2018.

[6] D. Sreenivasarao, P. Agarwal, and B. Das, "Neutral current compensation in three-phase, four-wire systems: A review," Electric Power Systems Research, vol. 86, no. May, pp. 170-180, 2012.

[7] O. \& B. M. GUL, "Power Quality and Neutral Current Problems From Unbalanced and Non-Linear Loads in Three-Phase Power Systems," 15th International Conference on Electricity Distribution, France., pp. 1-4, 1999.

[8] V. Jayalakshmi, "A method to reduce neutral current in three phase four wire electric distribution systems by using active power filter," Middle East Journal of Scientific Research, vol. 20, no. 11, pp. 1561-1564, 2014. 